\title{
Value of Online Medication Therapy Management Resources: Community Pharmacist Perspectives
} William R. Doucette, PhD ${ }^{1}$; Elaine Nguyen, PharmD ${ }^{1}$; Yiran Zhang, PhD Student ; Jane F. Pendergast, PhD ; Elizabeth A. Chrischilles, $P h D^{1}$; Karen B. Farris, $P h D^{2}$; and Jessica Frank, PharmD ${ }^{3}$

${ }^{1}$ University of lowa; ${ }^{2}$ University of Michigan; and ${ }^{3}$ OutcomesMTM

Acknowledgments: The authors wish to acknowledge Kristina Andino and Scott Egerton for their help with data collection. This study was supported by a grant from the Agency for Healthcare Research and Quality, \# 1R18HS18353.

Conflict of Interest: The authors declare no conflict of interests or financial interests in any product or service mentioned in this article, including grants, employment, gifts, stock holdings, or honoraria.

Key words: Medication therapy management, MTM, comprehensive medication review, CMR, medication adherence, elderly

\section{Article relevance and contribution to literature}

With the Centers for Medicare and Medicaid Services (CMS) mandating the delivery of medication therapy management (MTM), pharmacists have a unique opportunity to provide their patients with increased clinical services. However, there are barriers to MTM service delivery that need to be overcome and for many, additional training is needed. However, there is limited information on how best to provide training, the usefulness of practice tools, and pharmacists' perceptions of these tools. This paper highlights community pharmacists' attitudes toward and satisfaction with the MTM on-line training modules featuring the Tool to Improve Medications in the Elderly via Review (TIMER) and the DRug Adherence Work-up (DRAW) tool, as well as tips for integrating MTM services into pharmacy practice. This knowledge can aid in creating optimal MTM training tools and, upon implementation of tools, can help pharmacists address more patient issues and increase efficiency of pharmacist-provided MTM.

\section{Abstract}

Objectives: To describe pharmacists' attitudes toward and satisfaction with on-line training modules on MTM tools and tips for pharmacists and to characterize how useful the tools and concepts in the modules were to pharmacists when delivering MTM services.

Methods: Researchers distributed a web-based survey to pharmacists who had viewed the training modules that had been posted onto the training web site of OutcomesMTM. The majority of survey questions consisted of a 6-point Likert scale. Questions assessed pharmacists' opinions on the use of the tools. Information also was collected on implementing MTM tips, pharmacist demographics, and practice site characteristics.

Results: Respondents rated the Tool to Improve Medications in the Elderly via Review (TIMER) and DRug Adherence Work-up (DRAW) tools favorably across multiple items. Many pharmacists integrated the MTM tips into their practices, and reported increased efficiency in their delivery of MTM services.

Conclusion: Pharmacist training and tools such as the TIMER and DRAW tools plus MTM practice tips can assist pharmacists in providing MTM services to patients.

\section{Introduction}

Since implementation of Medicare Part D in 2006, the Centers for Medicare and Medicaid Services (CMS) has continued to refine medication therapy management (MTM) program requirements. ${ }^{1}$ As the primary provider of MTM services, this represents a unique opportunity for pharmacists. ${ }^{1}$ Studies in community pharmacies have shown that pharmacist-provided MTM services can improve

Corresponding author: William R. Doucette, PhD University of lowa, S518 PHAR, lowa City, IA 52242

Ph: 319-335-8786, Fax: 319-353-5646

Email: william-doucette@uiowa.edu outcomes and reduce costs. ${ }^{2-4}$ Pharmacies can also financially benefit from the provision of MTM services. ${ }^{5}$ Despite these advantages, pharmacists still face barriers to implementing MTM services in their practices such as lack of time, limited staffing, and difficulties locating educational MTM resources. ${ }^{6,7}$

Overcoming these barriers requires addressing pharmacists' training needs. ${ }^{8}$ There is limited information on how best to provide training, the actual usefulness of practice tools, and pharmacists' perceptions of these tools. Evaluating pharmacist experience with MTM training tools can aid in creating optimal tools and, upon implementation of tools, can 
ultimately increase efficiency of pharmacist-provided MTM services.

One study underway is working to improve and expand the MTM services pharmacists provide. This is the four-year Quality Improvement of Medication Therapy Management Services (QIMTM) study (AHRQ 1R18HS18353). One study aim is to enhance the way pharmacists deliver MTM services. To that end, the researchers have partnered with an MTM program coordinator (OutcomesMTM of West Des Moines, lowa) to conduct the AHRQ-funded quality improvement demonstration project. Two training modules were made available on OutcomesMTM's website, featuring tools pharmacists can use in providing MTM services: the Tool to Improve Medications in the Elderly via Review (TIMER) and the DRug Adherence Work-up (DRAW) tool. Each training module lasts about eight minutes. TIMER guides pharmacists as they comprehensively review issues of medication safety, effectiveness, and cost for older adults, through comprehensive medication reviews (CMRs). ${ }^{9}$ DRAW is intended to be used by pharmacists working with patients on medication non-adherence, and includes a set of questions to identify reasons for medication non-adherence, as well as suggested actions to address these reasons. ${ }^{10}$ MTM practice tips also are discussed as part of the DRAW training module. MTM practice tips included delegating appropriate components of MTM service processes to technicians, using an appointment system for MTM services, and developing an MTM champion among pharmacy staff.

While TIMER has been associated with an increase in pharmacists' and pharmacy students' ability to identify drug related-problems, additional information is needed about how such tools can be integrated into practice. ${ }^{9}$ Similarly, there is limited information on the use of the DRAW tool in pharmacy practice. ${ }^{10}$ This study collected feedback from pharmacists who viewed the on-line training videos about these tools, and then in some cases, used them in their practices when delivering MTM services.

\section{Objectives}

The objectives of this study were to 1) describe pharmacists' attitudes toward and satisfaction with the on-line training modules for TIMER and DRAW tools plus MTM tips, and 2) characterize how useful the tools and concepts in the modules were perceived by pharmacists in delivering MTM services.

\section{Methods}

Data were collected from pharmacists through a web-based survey. A link to the survey was sent to pharmacists who completed the post-test for one or both training modules.
The survey asked about both modules/tools, and a respondent could skip items about a module they did not view. Pharmacists encountered the training modules through either 1) receipt of an email or pop-up message in the OutcomesMTM online system informing them the training modules were available (because they participated in the QIMTM study) or 2) watching other Outcomes MTM training modules on the OutcomesMTM website. After viewing the training module(s), pharmacists completed a post-test which collected their names and email addresses. This contact information was sent to the researchers, who emailed pharmacists asking for their participation. The email message included elements of consent, the electronic link to the webbased survey, and an offer of an incentive for participation (\$20 gift card). Two reminder emails were sent to pharmacists who had not completed the survey, roughly two and four weeks after the initial contact. Researchers could see the names of pharmacists who had completed the survey, but could not link survey responses to individual participants.

The survey consisted of four parts: 1) pharmacists' attitudes toward and satisfaction with the training modules, 2) perceived usefulness of tools and MTM practice tips and times used, 3) personal demographic information, and 4) practice site characteristics. The first two survey parts consisted mainly of questions using a 6-point Likert scale (1 Strongly Disagree, 6 - Strongly Agree). Descriptive statistics were calculated for each survey item. The study was approved by the University of lowa Institutional Review Board.

\section{Results}

Of the 739 pharmacists invited to complete the survey, a total 121 responses were received (16.4\%), though not all of these were complete. Ninety-three respondents had viewed the TIMER training, 87 respondents had viewed the DRAW training plus MTM practice tips, while 73 respondents had viewed both. The majority of respondents were women (55.8\%) working in large chain community pharmacies (55.4\%). Over half (55.4\%) of the pharmacy practice sites dispensed no more than 250 prescriptions daily. (See Table 1 for a description of the participants and their practice sites.)

On average, respondents rated the TIMER $(\mathrm{N}=64)$ and DRAW $(\mathrm{N}=61)$ tools favorably across multiple items (Table 2$)$. The on-line surveys had skips built in, so only those reporting use of the TIMER or DRAW tools were asked to rate them. Over $95 \%$ of respondents who had used one of the tools perceived it as useful (mean \pm stnd dev) (TIMER $4.9 \pm 0.9$, DRAW $4.9 \pm$ $0.7)$ and agreed that they would recommend it to others (TIMER $5.0 \pm 0.9$, DRAW $5.0 \pm 0.8$ ). 
Since viewing the MTM practice tips portion of the DRAW training module, $43(60.6 \%)$ of the 71 respondents in this section reported adding an appointment system and 41 (57.7\%) respondents delegated MTM-related tasks (E.g. scheduling MTM appointments) to non-pharmacist personnel. Other changes that pharmacists made included adjusting staffing to create time dedicated to MTM services ( $n=34 ; 47.9 \%$ ), standardizing communication methods with prescribers ( $n=26 ; 36.6 \%$ ), and changing the documentation of MTM services ( $n=18 ; 25.4 \%$ ). Almost 90 percent of respondents reported some level of agreement that these changes helped increase the volume of MTM, while 93 percent agreed that these changes helped deliver MTM more efficiently.

\section{Discussion}

Overall, pharmacists had positive attitudes about TIMER, DRAW, and the MTM practice tips, while tool users also reported them helpful in enhancing their delivery of MTM services. The majority of respondents agreed that TIMER is a useful, well-organized, and easy-to-use tool. Other tools addressing medication use in the older adult population exist, including 1) the Screening Tool of Older Persons' potentially inappropriate Prescriptions (STOPP), 2) the Screening Tool to Alert doctors to Right Treatment (START), 3) the Improved Prescribing in the Elderly Tool (IPET), 4) and the Medication Appropriateness Index (MAI). STOPP/START is a validated tool, but it was not designed for use in MTM services and is used primarily to identify medications older adults should or should not be taking, based on physiological systems. ${ }^{11}$ Likewise, IPET is also a validated tool, but its use is limited to screening for inappropriate medications in the elderly. ${ }^{12}$ Unlike STOPP/START and IPET, the MAI has practitioners consider other indicators of medication appropriateness such as clinically significant drug interactions or least expensive alternatives. This may make the MAI more useful in the MTM setting compared to some of the other tools mentioned.

However, the MAl can be time-consuming to administer, and has limitations as it does not address adverse drug reactions or patient adherence like TIMER. ${ }^{13,14}$ The MAI was developed as a research tool to evaluate interventions. ${ }^{13}$

In contrast, TIMER was designed specifically for pharmacists to use when providing MTM services. TIMER guides pharmacists to consider multiple topics including patient safety (i.e. screening for safety, symptomology, adverse drug events, drug interactions, potentially inappropriate drugs, and duplication), adherence, attaining therapeutic goals, and cost.

The majority of respondents also agreed that DRAW is a useful, well-organized, and easy-to-use tool. Like TIMER,
DRAW was created for use in MTM service delivery. DRAW is best used to identify reasons for non-adherence and provides suggestions to increase adherence. ${ }^{10}$ It differs from other adherence tools like the Adherence Estimator, which is designed to determine the likelihood of adherence for a patient. ${ }^{15}$ The Adherence Estimator does not provide suggestions of ways to overcome adherence issues.

As tools, TIMER and DRAW can be used to guide an MTM session and their usefulness is likely strongest in individuals new to delivering MTM services. As a pharmacist gains experience using a tool and establishes a mental schema, he/she would be less likely to use an external tool. In addition, one survey respondent suggested that TIMER and DRAW tools could be helpful for those learning to deliver new services: "Great for first-timers and students." These tools can help pharmacy preceptors in supporting pharmacy students as they develop their own tailored mental schema for conducting an MTM session.

The MTM practice tips can help overcome barriers to MTM. A previous survey of community pharmacists in West Virginia found that lack of time was the most frequently perceived barrier to the provision of MTM services. ${ }^{7}$ Similarly, a national survey found that insufficient staffing was the most common barrier for pharmacists interested in providing MTM services. ${ }^{6}$ As the MTM practice tips are expected to increase the efficiency of MTM delivery with better time management, it is reasonable to presume that incorporating the tips from the training module could help address these obstacles. Of note, the majority of respondents somewhat agreed that the MTM practice tips helped increase the volume of MTM. The practice tips are intended to improve time management and workflow and are not necessarily intended to directly increase the volume of MTM services. However, an increase in the volume of MTM provided may be an indirect result of better MTM service organization in pharmacies.

\section{Limitations}

This study had some limitations. The response rate was $16.4 \%$ resulting in a small sample size and potential for nonresponse bias. Though the findings supported the usefulness of TIMER, DRAW and MTM practice tips, it is possible that the nonrespondents held less favorable views of the tools and tips. Another limitation is that the pharmacists who completed the survey were all MTM-registered pharmacists with OutcomesMTM, and may differ from the more general population of pharmacists. However, researchers did want feedback about how these tools affected the delivery of MTM services, and surveying pharmacists who have some MTM experience was desirable. 


\section{Conclusion}

Pharmacists' attitudes were positive towards the training modules covering TIMER and DRAW plus MTM practice tips. Overall, they reported that the tools helped them address more patient issues and that the practice tips helped them deliver MTM services more efficiently. Further research is needed to evaluate the effectiveness of such MTM practice tools on a larger scale, and to also compare tools with other MTM resources.

\section{References}

1. Centers for Medicare and Medicaid Services. 2011 Medicare Part D medication therapy management (MTM) programs fact sheet. Accessed at https://www.cms.gov/Medicare/

Prescription-Drug-

Coverage/PrescriptionDrugCovContra/downloads/MTMF actSheet 2011063011 Final.pdf, July 31, 2012.

2. Chrischilles EA, Carter BL, Lund BC, et al. Evaluation of the lowa Medicaid pharmaceutical case management program. J Am Pharm Assoc. 2004;44:337-49.

3. Bunting BA, Cranor CW. The Ashville Project: Long-term, clinical, humanistic, and economic outcomes of a community-based medication therapy management program for asthma. J Am Pharm Assoc. 2006;46:133-47.

4. Barnett MJ, Frank J, Wehring, $\mathrm{H}$, et al. Analysis of pharmacist-provided medication therapy management (MTM) services in community pharmacies over 7 years. J Manag Care Pharm. 2009;15:18-31.

5. McDonough RP, Harthan AA, McLeese KE, Doucette WR. Retrospective financial analysis of medication therapy management services from the pharmacy's perspective. J Am Pharm Assoc. 2010;50:62-6.

6. Lounsbery JL, Green CG, Bennett MS, Pedersen CA. Evaluation of pharmacists' barriers to implementation of medication therapy management services. 2009;49:51-8.

7. Blake KB, Madhavan SS. Perceived barriers to provision of medication therapy management services (MTMS) and the likelihood of a pharmacist to work in a pharmacy that provides MTMS. Ann Pharmacother. 2010;44:424-31.

8. Oladopo AO, Rascati KL. Review of survey articles regarding medication therapy management (MTM) services/programs in the United States. J Pharm Pract. 2012 Apr 27 [Epub ahead of print].
9. Lee SS, Schwemm AK, Reist J, et al. Pharmacists' and pharmacy students' ability to identify drug-related problems using TIMER (Tool to Improve Medications in the Elderly via Review). Am J Pharm Educ. 2009;73:52.

10. Doucette WR, Farris KB, Youland KE, et al. Development of the drug adherence work-up (DRAW) tool. J Am Pharm Assoc. 2013; forthcoming.

11. Gallagher P, Ryan C, Bryne S, et al. STOPP (screening tool of older person's prescriptions and START (screening tool to alert doctors to right treatment). Consensus validation. Int J Clin Pharmacol Ther. 2008;46:72-83.

12. Naugler CT, Brymer C, Stolee P, Arcese ZA. Development and validation of an improved prescribing in the elderly tool. Can J Clin Pharmacol. 2000;7:103-7.

13. Hanlon JT, Schmade KE, Samsa GP, et al. A method for assessing drug therapy appropriateness. J Clin Epidemiol. 1992;45:1045-51.

14. Kassam R, Martin LG, Farris KB. Reliability of a modified medication appropriateness index in community pharmacies. Ann Pharmacother. 2003;37:40-6.

15. McHorney CA. The adherence estimator: a brief, proximal screener for patient propensity to adhere to prescription medications for chronic disease. Curr Med Res Opin. 2009;25:215-38. 
Table 1 Description of Respondents and Practice Sites

\begin{tabular}{|c|c|}
\hline Characteristics & Result \\
\hline \multicolumn{2}{|l|}{ Gender, $N(\%)(n=120)$} \\
\hline Male & $53(44.2)$ \\
\hline Female & $67(55.8)$ \\
\hline \multicolumn{2}{|l|}{ Year of Practice (years) $(n=121)$} \\
\hline Median (Range) & $12.0(0.5-51.0)$ \\
\hline \multicolumn{2}{|l|}{ Pharmacy Training, N (\%) $(n=121)$} \\
\hline BS Pharm & $56(46.3)$ \\
\hline Pharm D & 66 (54.5) \\
\hline Residency & 11 (9.1) \\
\hline Other & 7 (5.8) \\
\hline \multicolumn{2}{|l|}{ Pharmacy Site, N (\%) (n=121) } \\
\hline Large Chain Community Pharmacy & $67(55.4)$ \\
\hline Independent Community Pharmacy & $21(17.4)$ \\
\hline Supermarket Pharmacy & $17(14.0)$ \\
\hline Mass Merchandiser & $5(4.1)$ \\
\hline Small Chain Community Pharmacy & $4(3.3)$ \\
\hline Other & $7(5.8)$ \\
\hline \multicolumn{2}{|c|}{ Number of MTM Clients Monthly Pharmacy, N (\%) $(n=120)$} \\
\hline$\leq 10$ & $78(65.0)$ \\
\hline $11-20$ & $25(20.8)$ \\
\hline $21-30$ & 4 (3.3) \\
\hline $31-40$ & $6(5.0)$ \\
\hline$\geq 40$ & 7 (5.8) \\
\hline \multicolumn{2}{|c|}{ MTM Time Weekly Individual (hours) ( $n=119$ ) } \\
\hline Median (Range) & $3.0(0.0-42.0)$ \\
\hline \multicolumn{2}{|c|}{ Practice Time Weekly Individual (hours) ( $n=120$ ) } \\
\hline Median (Range) & $40.0(0.0-101.0)$ \\
\hline \multicolumn{2}{|c|}{ Number of Pharmacy Staff, Median (Range) ( $n=121)$} \\
\hline Pharmacists & $1.0(0.0-8.0)$ \\
\hline Residents & $0.0(0.0-1.0)$ \\
\hline Technicians & $2.0(0.0-80.0)$ \\
\hline Clerks & $0.0(0.0-40.0)$ \\
\hline Other & $0.0(0.0-20.0)$ \\
\hline \multicolumn{2}{|c|}{ Number of Prescriptions Daily, $N(\%)(n=121)$} \\
\hline$\leq 150$ & $25(20.7)$ \\
\hline $151-250$ & $42(34.7)$ \\
\hline $251-350$ & $29(24.0)$ \\
\hline$\geq 350$ & $25(20.7)$ \\
\hline
\end{tabular}

- For pharmacy training, respondents could check all that applied 
Table 2 Rating of MTM Tools

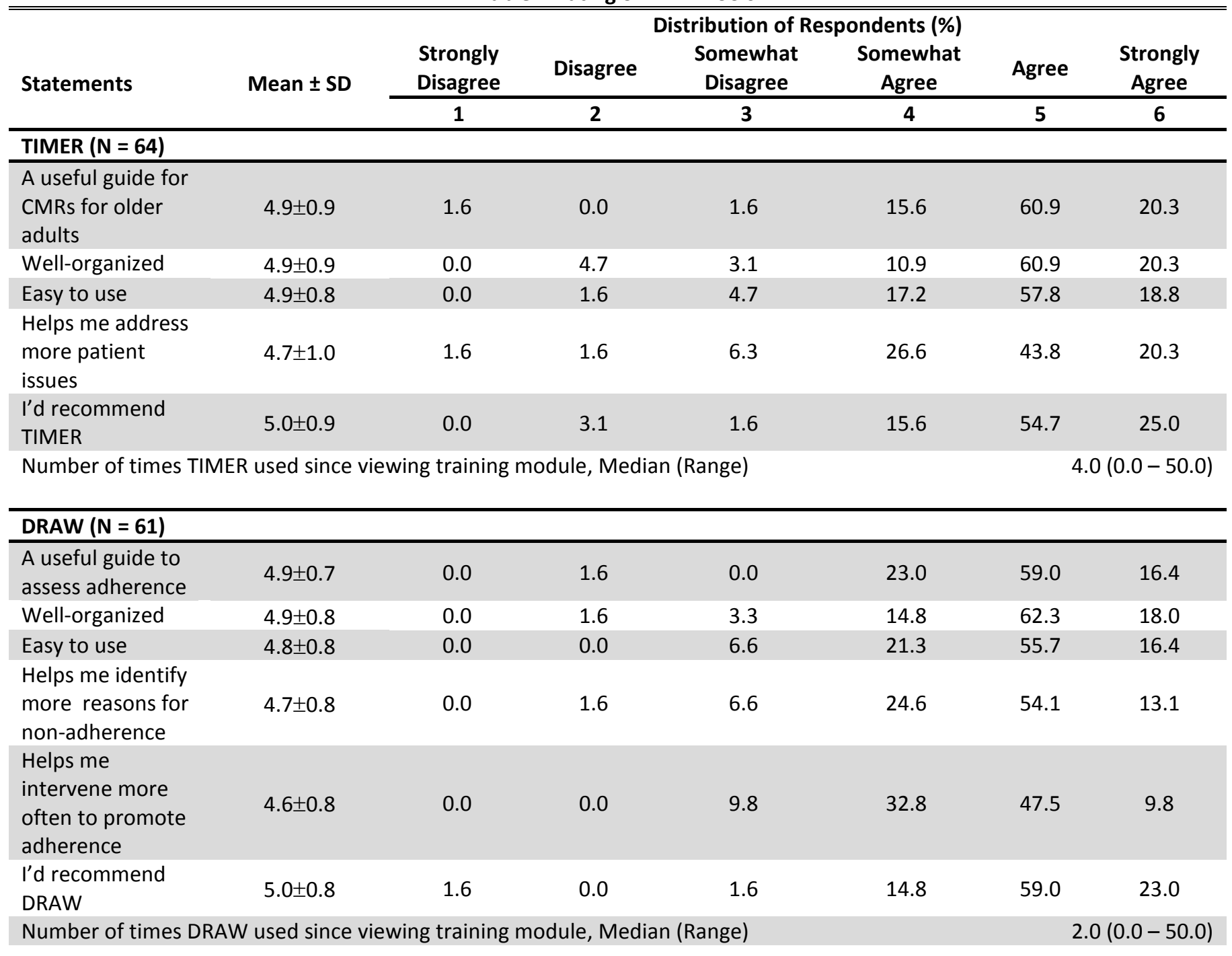

